\title{
A Study of the Proteinase Activity Released by Dictyostelium discoideum during Starvation
}

\author{
By MICHAEL J. NORTH \\ Department of Biochemistry, University of Stirling, Stirling FK9 4LA, U.K.
}

(Received 4 November 1981; revised 18 December 1981)

The release of proteinase activity from myxamoebae of Dictyostelium discoideum after suspension in non-nutrient buffer has been confirmed. Between $15 \%$ and $30 \%$ of the total activity against Hide Powder Azure was released, the bulk of this appearing in the buffer within $30 \mathrm{~min}$. Activity against the cathepsin B substrate, $\alpha$-benzoyl-DL-arginine 2-naphthylamide, was also released. The release of proteinase activity was more rapid than that of other secreted lysosomal enzymes and was insensitive to cyanide. The extracellular proteinases catalysed both limited and extensive proteolysis. Gel electrophoresis showed similar patterns of released and intracellular proteinases, and their sensitivities to inhibitors were also similar. However, there was evidence for an increased proportion of thiol proteinases in the released enzymes. The results suggest that proteinases were released by a non-secretory process but one possible mechanism, cell lysis, has not been clearly demonstrated. A specific developmental role for extracellular proteinases seems unlikely.

\section{INTRODUCTION}

Rossomando et al. (1978) and Crean et al. (1981) have described the release of proteinase activity from myxamoebae of the cellular slime mould Dictyostelium discoideum starved in shaken suspensions. They suggested that the proteolytic activity plays a role in modifying the cell membrane components facilitating migration and multicellular structure function. Other workers have shown that $D$. discoideum possesses more than one proteinase activity (North \& Harwood, 1979; Fong \& Rutherford, 1978) and so it was of interest to determine which of these were released upon starvation. Rossomando et al. (1978) had carried out only a limited characterization of the activity and demonstrated that it was optimally active against Hide Powder Azure between $\mathrm{pH} 3$ and 5 and was not inhibited by three proteinase inhibitors, ruling out a contribution from metallo- or serine-proteinases. This report describes a further characterization of the activity and shows that it was due to multiple forms of proteinase.

The kinetics of release have been further examined and experiments are described which rule out the possibility that the appearance of proteinase activity outside the cells was due to an active secretory process.

\section{METHODS}

Organism and growth conditions. Dictyostelium discoideum strain AX2 ATCC 24397 was grown in HL5 medium 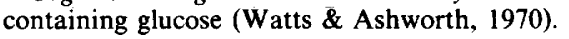

Harvesting and starvation conditions. Myxamoebae were harvested during the exponential phase (cell density between $4 \times 10^{6}$ and $8 \times 10^{6}$ cells $\mathrm{ml}^{-1}$ ) by centrifugation at room temperature for $30 \mathrm{~s} \mathrm{at} 800 \mathrm{~g}$ in an MSE Minor bench centrifuge. The cells were washed in an equal volume of $10 \mathrm{~mm}$-potassium phosphate buffer, $\mathrm{pH} 6 \cdot 0$, and collected by centrifugation. They were resuspended in potassium phosphate buffer at a density of $1 \times 10^{7}$ cells $\mathrm{ml}^{-1}$ and shaken at $110 \mathrm{rev}$. $\mathrm{min}^{-1}$ in a Gallenkamp orbital incubator at $22^{\circ} \mathrm{C}$. These conditions were similar to the Standard Secretion Conditions of Dimond et al. (1981) but differed in that the cells were harvested more

Abbreviations: BANA, $N$ - $\alpha$-benzoyl-DL-arginine 2-naphthylamide; DTT, dithiothreitol; TLCK, $N$ - $\alpha$ - $p$-tosylL-lysine chloromethyl ketone. 
rapidly and at a lower cell density. Rossomando et al. (1978) probably employed a longer harvesting period and included $2 \mathrm{mM}-\mathrm{MgSO}_{4}$ in their resuspension buffer.

Supernatants for the determination of extracellular activity and cell pellets for intracellular activity were collected by centrifuging samples in $10 \mathrm{ml}$ graduated conical glass tubes in a fixed-angle rotor for $30 \mathrm{~s}$ at $800 \mathrm{~g}$. After removing the supernatant the cell pellet was resuspended in potassium phosphate buffer. The samples were either assayed immediately or stored at $-20^{\circ} \mathrm{C}$ until required. Immediately before assaying, $0 \cdot 1 \%(v / v)$ Triton $\mathrm{X}$ 100 was added to both cell suspensions and supernatants.

Enzyme assays. All assays were carried out at $30^{\circ} \mathrm{C}$. Proteinase activity was measured using Hide Powder Azure as substrate. Two methods of estimating activity were employed. In both methods $0-200 \mu 1$ of sample was shaken with $500 \mu \mathrm{l}$ of $0.1 \mathrm{M}$-sodium acetate/acetic acid buffer, pH 3.5, and $500 \mu \mathrm{l}$ of a suspension of Hide Powder Azure ( $10 \mathrm{mg} \mathrm{ml}^{-1}$ in water). In method $\mathrm{A}$, the reaction was stopped by centrifugation in a Jobling microcentrifuge (model 320) for $5 \mathrm{~min}$. The release of substrate into the supernatant was determined from the absorbance at $595 \mathrm{~nm}$. In method B, $200 \mu \mathrm{l}$ of $50 \%$ (w/v) TCA was added prior to centrifugation. The two methods could be combined by adding TCA to the samples after the first centrifugation and absorbance readings had been made.

Hydrolysis of $N$ - $\alpha$-benzoyl-DL-arginine 2-naphthylamide. $\mathrm{HCl}$ (BANA) was assayed by Barrett's (1972) method.

$\beta$ - $N$-Acetylglucosaminidase was assayed as described by Loomis (1969), acid phosphatase as described by Dimond et al. (1981) and $\beta$-galactosidase as described by Dimond et al. (1976), but using $0 \cdot 1 \mathrm{M}$-sodium acetate/acetic acid buffer, $\mathrm{pH} 3 \cdot 0$, and adding 2 vol. $(1.0 \mathrm{ml})$ of $1 \mathrm{M}-\mathrm{Na}_{2} \mathrm{CO}_{3}$ to stop the reaction.

Inhibition conditions. The effect of proteinase inhibitors was tested by preincubating samples with inhibitors for $1 \mathrm{~h}$ at room temperature before assaying as above. For iodoacetate, $N-\alpha-p$-tosyl-L-lysine chloromethyl ketone (TLCK), $\mathrm{HgCl}_{2}$ and aminophenylmercuric acetate, the inhibitor was present at $1 \mathrm{~mm}$ and the samples included $0.1 \mathrm{M}$-sodium phosphate/citric acid buffer, $\mathrm{pH}$ 6.5. For leupeptin the same buffer was used but the inhibitor was present at $100 \mu \mathrm{g} \mathrm{ml}^{-1}$. Pepstatin was also present at $100 \mu \mathrm{g} \mathrm{ml}^{-1}$ but in $0 \cdot 1 \mathrm{M}$-sodium acetate/acetic acid buffer, $\mathrm{pH} 3 \cdot 5$.

Electrophoretic analysis of proteinase activity. A sample of supernatant was concentrated 20-fold by freeze-drying and then dialysed against potassium phosphate buffer. Samples of this and a dialysed extract of the corresponding cells were applied to polyacrylamide gels and analysed for proteinase activity exactly as described previously (North \& Harwood, 1979; Kost et al., 1981).

Chemicals. All substrates for enzyme assays were supplied by Sigma, except 4-nitrophenyl phosphate which was from BDH. Leupeptin and pepstatin were supplied by Protein Research Foundation, Osaka, Japan, and other proteinase inhibitors and DTT by Sigma. All other chemicals were of the highest purity commercially available.

\section{RESULTS AND DISCUSSION}

During the period immediately after resuspension of AX2 myxamoebae in potassium phosphate buffer, proteinase activity appeared in the buffer, thus confirming the observations made with another axenic strain, AX3, by Rossomando et al. (1978) and Crean et al. (1981). Figure 1 shows the kinetics of appearance of extracellular proteinase activity, given as a percentage of the total activity (intracellular plus extracellular); for comparison, it also shows the release of two other hydrolases, $\beta$ - $N$-acetylglucosaminidase and acid phosphatase. Most of the extracellular proteinase activity had appeared within $30 \mathrm{~min}$, whilst acid phosphatase and $\beta$ - $N$-acetylglucosaminidase reached maximum values after 60 to $90 \mathrm{~min}$. In these experiments, therefore, the parallel release of proteinase and glycosidase activities shown by Rossomando et al. (1978) was not observed. The percentage of the total proteinase released was also greater than the $10 \%$ reported by Crean et al. (1981). Dimond et al. (1981) noted that the release of acid phosphatase activity by strain AX3 was slower than reported by de Chastellier \& Ryter (1977) for strain AX2. The more rapid release noted by de Chastellier \& Ryter (1977) was again observed in the present experiments (Fig. 1), suggesting that the difference may be strain dependent.

Dimond et al. (1981) demonstrated that the release of many lysosomal hydrolases can be blocked by cyanide, consistent with an energy-dependent secretion process. Surprisingly, the release of proteinase was cyanide-insensitive (Fig. 1, Table 1), despite the fact that the release of other hydrolases from the same suspensions was inhibited. An exception to this was $\beta$-galactosidase. This activity was assayed at $\mathrm{pH} 3$, and a high proportion of the activity at this $\mathrm{pH}$ would have been due to $\beta$-galactosidase-2 (Dimond et al., 1976), which Dimond et al. (1981) have shown is released in very small amounts and may not be secreted. A low percentage of the total $\beta$ galactosidase activity appeared in the buffer in these experiments as well (Table 1).

Extracts of $D$. discoideum can also hydrolyse the cathepsin B substrate BANA (Fong \& 


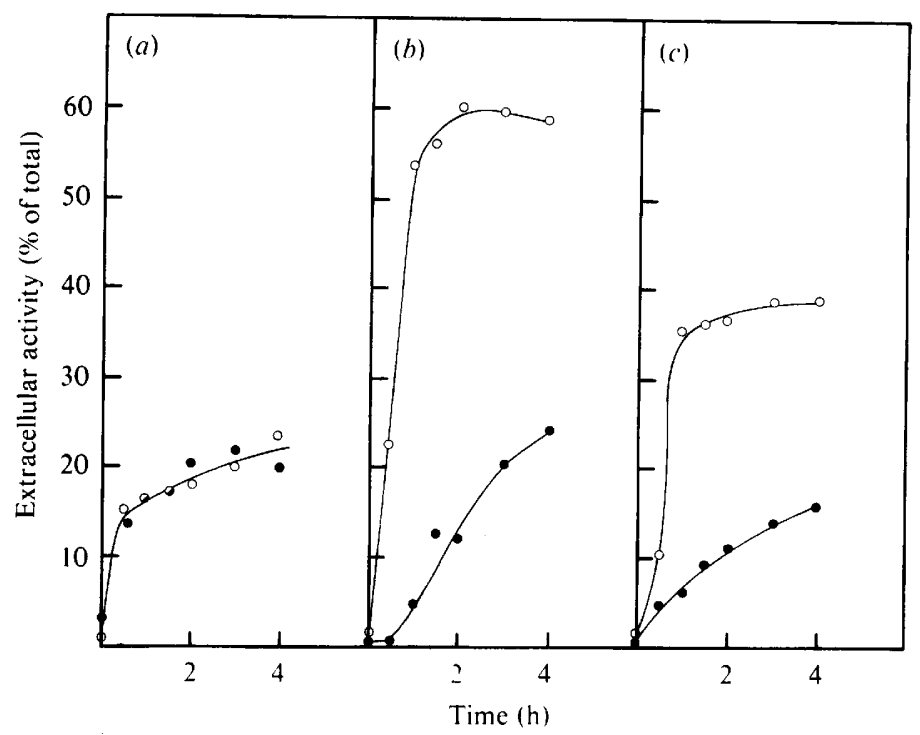

Fig. 1. Release of hydrolytic enzymes and the effect of cyanide. Two suspensions were set up from a single growth culture: for one suspension $10 \mathrm{mM}-\mathrm{KCN}$ was added to the buffer. Samples were taken periodically and assayed for (a) proteinase, method $\mathrm{A},(b) \beta$ - $N$-acetylglucosaminidase and (c) acid phosphatase. Untreated control $(O)$; cyanide-treated suspension $(O)$.

\section{Table 1. Effect of cyanide on the release of hydrolytic enzymes}

Two cell suspensions were set up from each of four independent growth cultures as described in Methods. For one of each pair of suspensions $10 \mathrm{mM}-\mathrm{KCN}$ was included in the resuspension buffer. After $2 \mathrm{~h}$ incubation, cell samples and supernatants were collected. After addition of $0.1 \%(\mathrm{v} / \mathrm{v})$ Triton $\mathrm{X}-100$ each was assayed for enzyme activity. Values for individual cyanide-treated suspensions were calculated relative to those for their corresponding control suspensions. The results are the mean values from the four sets of suspensions and are given \pm standard deviation.

Percentage of total activity in supernatant

Enzyme

Proteinase

BANA hydrolase

$\beta$ - $N$-Acetylglucosaminidase

$\beta$-Galactosidase

Acid phosphatase

Control
$29.7 \pm 1.5$
$16.5 \pm 6.6$
$65.8 \pm 2.4$
$7.5 \pm 1.7$
$51.5 \pm 3.7$

Cyanide-treated

$28.5 \pm 3.4$
$19.3 \pm 3.6$
$22.0 \pm 2.2$
$8.7 \pm 2.8$
$15.8 \pm 3.4$

Ratio of cyanide-treated to control

$0.96 \pm 0.11$
$1.45 \pm 0.72$
$0.33 \pm 0.03$
$1.17 \pm 0.33$
$0.31 \pm 0.07$

Rutherford, 1978) and BANA-hydrolysing activity appeared in the buffer during starvation (Table 1). Although there was more variation in the amount in the buffer, its release too was insensitive to cyanide.

The method used above for assaying proteinase activity with Hide Powder Azure (method A) was similar to that used by Rossomando et al. (1978), except that a lower $\mathrm{pH}$ was used ( 3.5 instead of 4) and the digested substrate was separated from the undigested insoluble substrate by centrifugation rather than by filtration. However, this method differs from one I have employed previously (method B) (North, 1978) in which TCA is added to stop the reaction prior to centrifugation of undigested material. Method A consistently gave a higher estimate of activity than method B, which is not surprising since the products remaining in solution in method $\mathbf{A}$ represent both large (acid-insoluble) and small (acid-soluble) polypeptide fragments, whilst only the latter remain soluble in method B. This was confirmed by adding TCA to the supernatant from Method A, which caused blue material to be precipitated. Thus, method A gives an estimate of both limited and extensive proteolysis whilst method B provides an estimate of extensive hydrolysis only. An analysis of the results of a number of assays in which both methods 


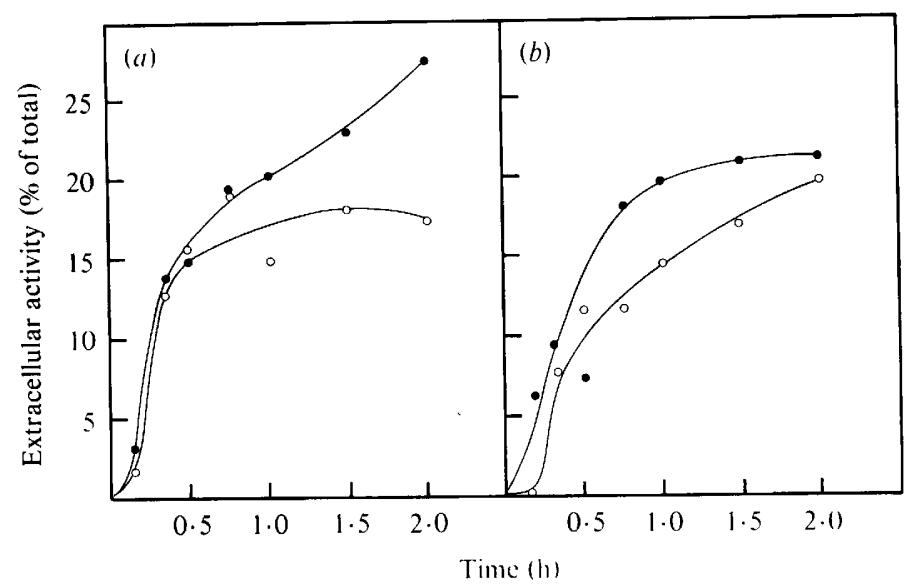

Fig. 2. Release of proteinase activity assayed by methods A and B, with and without DTT. Samples taken periodically after suspension of myxamoebae in buffer were assayed for proteinase by $(a)$ method $A$ or $(b)$ method B. Untreated control $(O) ; 1$ mM-DTT included in assay $(O)$.

were used showed that the values from method $A$ were usually between 2-and 3-fold greater than those from method B. When $1 \mathrm{mM}$-DTT was included in the assay system it enhanced proteinase activity and method $A$ then gave values between 1.5- and 2-fold greater than method B, suggesting that DTT activated extensive proteolysis to a greater extent than limited proteolysis. DTT would activate thiol proteinases already known to be present in $D$. discoideum (North \& Harwood, 1979; Fong \& Rutherford, 1978; Gustafson \& Thon, 1979).

Since the method of assay might have affected the kinetics observed for proteinase release, an experiment was carried out in which samples were assayed by both methods. The effect of DTT was also checked. The results (Fig. 2) show that whichever assay method was used, there was a rapid appearance of proteinase activity in the buffer. Similar results were obtained using a different cell suspension. Evidently, the enzyme(s) responsible catalysed both limited and extensive proteolysis. A higher percentage of proteinase release was apparent when DTT was included in the assay system, suggesting that the extracellular proteinases were slightly enriched in thiol-dependent enzymes.

To determine how many forms of proteinase were released, cell samples and material concentrated from supernatants were analysed by electrophoresis on polyacrylamide gels containing denatured haemoglobin. Proteinases were visualized as clear bands where haemoglobin was digested. Figure 3 shows the pattern of the proteinases active at $\mathrm{pH} 2$ and at $\mathrm{pH} 4$. Clearly, multiple proteinases were present both intracellularly and extracellularly and only some small differences were seen. In these samples a double band was observed in the region corresponding to proteinase D where a single band had been observed previously (North \& Harwood, 1979).

Table 2 compares the sensitivity of the intracellular and extracellular proteinase activities to various inhibitors, determined by assay method B; similar results were obtained with method A. The intracellular activity showed a pattern of sensitivity similar to that previously reported (North \& Harwood, 1979), i.e. slight inhibition by some thiol proteinase inhibitors (iodoacetate and leupeptin), no inhibition with pepstatin and complete inhibition with mercuric chloride and aminophenylmercuric acetate. The mercurial inhibition was reversed by DTT. The DTTenhanced activity was more sensitive to the other thiol proteinase inhibitors including TLCK. This was not surprising since DTT activates thiol proteinases specifically. A similar pattern of inhibition was observed for the extracellular activity except that in the presence of DTT the thiol proteinase inhibitors had a greater effect than they had on the intracellular activity.

The results of this study show that almost immediately after suspension of myxamoebae in phosphate buffer, multiple proteinase activities are released into the buffer. From the results in Fig. 2 and Table 2 it appears that thiol proteinases make a slightly increased contribution to the extracellular activity. BANA-hydrolysing activity, which was released from the cells (Table 1), would also be expected to be due to one or more thiol proteinases. 


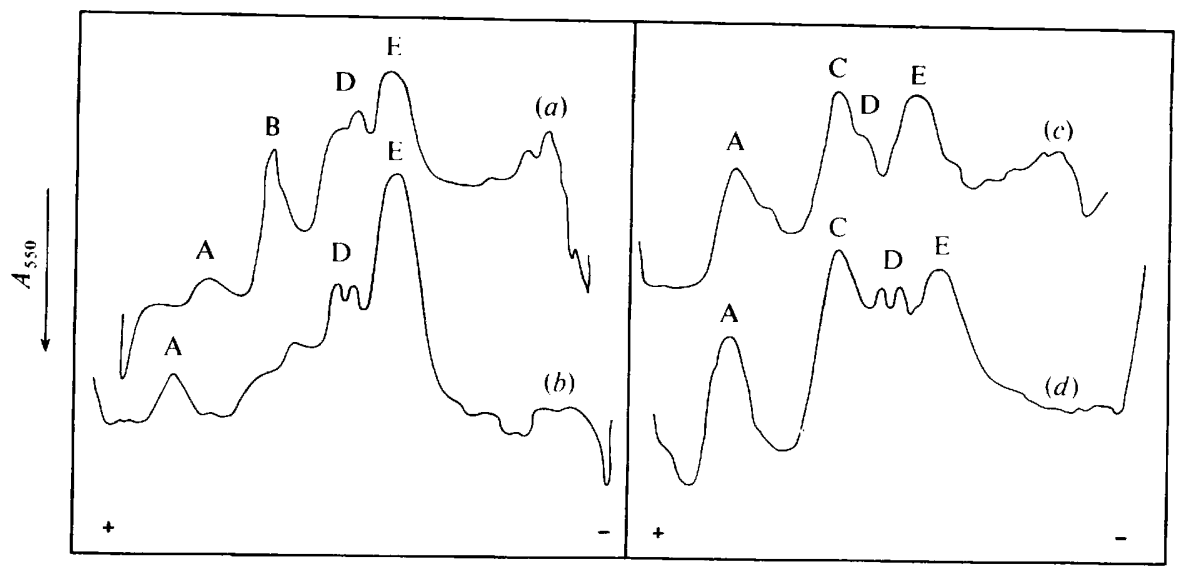

Fig. 3. Densitometric scans of proteinase patterns on polyacrylamide gels containing denatured haemoglobin: $(a)$ cell sample and $(b)$ supernatant, gels incubated at pH 2 for $2 \mathrm{~h} ;(c)$ cell sample and $(d)$ supernatant, gels incubated at $\mathrm{pH} 4$ for $19 \mathrm{~h}$. 1 mM-DTT was included for all incubations. Scans represent the whole gels and all visible bands are labelled according to the scheme of North \& Harwood (1979).

\section{Table 2. Effect of inhibitors on released and cellular proteinase activity}

Supernatant (containing released activity) and cells were collected $2 \mathrm{~h}$ after resuspension. Data are presented for activity assayed by method B with $1 \mathrm{~mm}$-DTT added during the assay where indicated. Activities are given relative to those of controls preincubated without inhibitors. The effect of DTT on the control activity is also shown.

\begin{tabular}{|c|c|c|c|c|}
\hline \multirow[b]{3}{*}{ Inhibitor } & \multicolumn{4}{|c|}{ Relative proteinase activity } \\
\hline & \multicolumn{2}{|c|}{ Cells } & \multicolumn{2}{|c|}{ Supernatant } \\
\hline & No DTT & + DTT & No DTT & + DTT \\
\hline $\begin{array}{l}\text { Pepstatin } \\
\text { Leupeptin } \\
\text { Iodoacetate } \\
\text { TLCK } \\
\mathrm{HgCl}_{2} \\
\text { Aminophenylmercuric acetate }\end{array}$ & $\begin{array}{l}0.86 \\
0.76 \\
0.86 \\
0 \cdot 71 \\
0 \\
0\end{array}$ & $\begin{array}{l}1 \cdot 07 \\
0 \cdot 66 \\
0 \cdot 69 \\
0 \cdot 61 \\
0 \cdot 77 \\
0 \cdot 71\end{array}$ & $\begin{array}{l}1.09 \\
0.84 \\
1.02 \\
0.86 \\
0.03 \\
0\end{array}$ & $\begin{array}{l}1.09 \\
0 \cdot 33 \\
0.56 \\
0.46 \\
0.63 \\
0.61\end{array}$ \\
\hline Control (+DTT/no DTT) & \multicolumn{2}{|c|}{$1 \cdot 58$} & \multicolumn{2}{|c|}{1.79} \\
\hline
\end{tabular}

The mechanism of proteinase release is not readily apparent. The proteinases detected here are almost certainly located within lysosomes (Wiener \& Ashworth, 1970; M. J. North, unpublished observations). Nevertheless, they cannot be released from the same lysosomal vesicles as other hydrolases such as acid phosphatase and $\beta$ - $N$-acetylglucosaminidase. Their kinetics of release differed and release was not cyanide-sensitive.

The insensitivity of proteinase release to cyanide suggests that the release mechanism is not a specific secretory process, since this would be expected to be energy-dependent and so inhibited by cyanide. The possibility that proteinase release occurred more rapidly than cyanide-inhibited metabolism is unlikely in view of the speed at which cyanide inhibited the release of other hydrolases (Fig. 1). This possibility was eliminated completely when it was shown that cells treated with cyanide for $30 \mathrm{~min}$ prior to harvesting and transfer to cyanide-containing buffer were still able to release proteinase activity. Indeed, after $30 \mathrm{~min}$ in buffer the activity released was almost twice that released by untreated cells. A mechanism that would have been insensitive to cyanide is one resulting from cell lysis. However, the data in Table 1 show that the percentage of proteinase activity released was greater than that of $\beta$-galactosidase which $\mathrm{Di}$ mond et al. (1981) believe is probably released by cell lysis. However, it is possible that the percentages for extracellular proteinase activity are overestimates, because of the differential 
presence of inhibitors in the fractions. These might be specific endogenous inhibitors such as those described for yeast (Wolf \& Holzer, 1980), but other endogenous proteins that are simply good substrates for the proteinases could compete in the assays with the Hide Powder Azure. Since such inhibition is less likely to occur in supernatant samples, the effect of this would be to overestimate the percentage of activity in the supernatant. However, when samples in which the cells were not separated from the supernatant were assayed, the activity was the same as that of the sum of the activities of cells and supernatant assayed separately. Thus, extracellular proteinase activity at least was not significantly affected by factors in the cell samples under these conditions.

If release were due to cell lysis then its extent might reflect the treatment of the cells before resuspension in buffer or even during sampling. The method chosen for harvesting the cells was the gentlest available. Extending the centrifugation time to $2 \mathrm{~min}$ or including an additional washing step did not affect the percentage of proteinase released after $30 \mathrm{~min}$. However, lower percentages were sometimes observed if cells were harvested by centrifugation at $5000 \mathrm{~g}$ for $5 \mathrm{~min}$, the method probably used by Rossomando et al. (1978). In view of the rapidity of proteinase release it would not be surprising if extended harvesting and washing procedures result in loss of activity from the cells before they are resuspended in buffer. However, some proteinase release, albeit at a reduced level, occurred when cells were washed and resuspended in nutrient medium (HL5 medium plus glucose), suggesting that the process of centrifugation may be responsible in part for triggering the loss. The involvement of an additional factor, lowered osmolality, was also suggested since the release of proteinase was reduced when a higher concentration of buffer $(100 \mathrm{mM})$ was used or when $100 \mathrm{mM}-\mathrm{NaCl}$ was added to the $10 \mathrm{mM}$ buffer. That centrifugation was not the only factor involved was also indicated by the fact that cells allowed to settle on to the base of tissue culture dishes also released proteinase when the nutrient medium was replaced by buffer. The use of longer or faster centrifugation for sampling the cells from buffer did not affect the distribution of proteinase activity.

Whatever the mechanism of proteinase release, it clearly differed from that for many other lysosomal hydrolases. On the basis of the pattern of secretion of various enzymes, Dimond et al. (1981) have suggested that there are three functional classes of lysosomal vesicles, two involved in secretory processes and one which is non-secretory. $\beta$-Galactosidase- 2 was considered to be an enzyme from the latter class of vesicle, and it was noted that its $\mathrm{pH}$ optimum was lower than that of the secreted lysosomal enzymes, indicating a possible difference in internal environment. It is noteworthy that the proteinases also have low pH optima and so may be contained in lysosomal vesicles belonging to the third, non-secretory class. Crean et al. (1981) have also shown that, unlike $\beta$ - $N$-acetylglucosaminidase and acid phosphatase secretion, proteinase release is not affected by hadacidin.

Proteinase release occurred by a passive and, therefore, non-secretory mechanism and it is tempting to speculate that this was triggered not by starvation, but by the abrupt perturbation of the external environment during harvesting and resuspension in non-nutrient buffer. Since such a complex and dramatic perturbation is unlikely to occur at the natural onset of starvation, some doubt must be cast on the model proposed by Rossomando et al. (1978). For a specific developmental role, enzyme release might be expected to be a more controllable and energy-dependent process and not achieved by the cyanide-insensitive mechanism indicated here.

This work was supported by a grant from the Science and Engineering Research Council. I wish to thank Anne Whyte for excellent technical assistance.

\section{REFERENCES}

BARRETT, A. J. (1972). A new assay for cathepsin B1 and other thiol proteinases. Analytical Biochemistry 47, 280-293.

Crean, E. V., Lagerstedt, J. P. \& Rossomando, E. F. (1981). Lysosomal abnormalities in hadacidin-treated Dictyostelium discoideum amoebae. Journal of General Microbiology 123, 253-257. de Chastellier, C. \& Ryter, A. (1977). Changes of the cell surface and of the digestive apparatus of Dictyostelium discoideum during the starvation period triggering aggregation. Journal of Cell Biology 75, 218-236.

Dimond, R. L., MAYeR, M. \& LoOMIS, W. F. (1976). Characterization and developmental regulation of $\beta$ - 
galactosidase isozymes in Dictyostelium discoideum. Developmental Biology 52, 74-82.

Dimond, R. L., BURNS, R. A. \& JoRdAN, K. B. (1981). Secretion of lysosomal enzymes in the cellular slime mould Dictyostelium discoideum. Developmental Biology 52, 74-82.

FONG, D. \& RUTHERFoRD, G. L. (1978). Protease activity during cell differentiation of the cellular slime mould Dictyostelium discoideum. Journal of Bacteriology 134, 521-527.

Gustafson, G. L. \& Thon, L. A. (1979). Purification and characterization of a proteinase from Dictyostelium discoideum. Journal of Biological Chemistry 254, 12471-12478.

Kost, R. G., NoRTh, M. J. \& WhYTE, A. (1981). Acid proteinases in various species of cellular slime mould. Experimental Mycology 5, 269-277.

Loomis, W. F. (1969). Acetylglucosaminidase, an early enzyme in the development of Dictyostelium discoideum. Journal of Bacteriology 97, 1149-1154.

NoRTH, M. J. (1978). Inhibition of acid proteinase from Dictyostelium discoideum. Biochemical Society Transactions 6, 400-403.
NORTH, M. J. \& HARwoOd, J. M. (1979). Multiple acid proteinases in the cellular slime mould Dictyostelium discoideum. Biochimica et biophysica acta 566, 222233.

Rossomando, E. F., Maldonado, B., Crean, E. V. \& Kollar, E. J. (1978). Protease secretion during onset of development in Dictyostelium discoideum. Journal of Cell Science 30, 305-318.

WATTS, D. J. \& ASHWORTH, J. M. (1970). Growth of myxamoebae of the cellular slime mould Dictyostelium discoideum in axenic culture. Biochemical Journal 119, 171-174.

WIENER, E. \& AsHWORTH, J. M. (1970). The isolation and characterization of lysosomal particles from myxamoebae of the cellular slime mould Dictyostelium discoideum. Biochemical Journal 118, 505512.

Wolf, D. H. \& Holzer, H. (1980). Proteolysis in yeast. In Microorganisms and Nitrogen Sources, pp. 431-458. Edited by J. W. Payne. London: John Wiley. 